\title{
A Structural form Default Prediction Model for SMEs, Evidence from the Dutch Market
}

\author{
Frieda Rikkers* \\ Tilburg University, Netherlands \\ André E. Thibeault \\ Vlerick Leuven Gent Management School, Belgium
}

\begin{abstract}
The objective of this research is to develop a structural form probability of default model for small and medium-sized enterprises, dealing with the methodological issues which arise in the modelling of small commercial loan portfolios. Other motivations are to provide an extensive overview of the characteristics of SMEs, and to provide a list of characteristics for an SME $P D$ model, e.g. time and cost efficiency, broad applicability, limited data requirements, and powerful in predicting default. The structural form model is developed and tested on a unique dataset of private firm's bank loans of a Dutch bank. The results are promising; the model output differs significantly between defaulted and non-defaulted firms. The structural form model can be used on its own, or as an additional variable in a credit risk model. A second $P D$ model is developed using logistic regression with a number of financial ratios, including the structural form measure. This variable is significant in default prediction of SMEs and has some additional predictive power, next to the popular financial ratios. Overall, the results indicate that the structural form model is a good indicator for default of SMEs. (JEL: C51, C52, G21, G28, G33)
\end{abstract}

Keywords: Default probability, structural form credit risk model, Basel II

\footnotetext{
${ }^{*}$ Faculty of Economics and Business Administration, Tilburg University, Postbus 9015, 35000 LE, Tilburg, the Netherlands. E-mail: f.rikkers@uvt.nl, T +31 13 4668902. We thank Philip Joos, Willem Buijink, Graham Partington, Richard Taffler, Susan Carpenter, Hans Jacobs, Marjolein van Scheppingen, Marcel Peeters, and participants of the Multinational Finance Society Conference for helpful comments and valuable discussions. We thank the financial institution for providing the data.
}

(Multinational Finance Journal, 2009, vol. 13, no. 3/4, pp. 229-264)

(C) Multinational Finance Society, a nonprofit corporation. All rights reserved.

DOI: $10.17578 / 13-3 / 4-4$ 


\section{Introduction}

One of the highest risks a bank faces is the risk that one of the bank's counterparties goes into default, not repaying interest and/or principal. A solid framework for measuring credit risk is therefore of the utmost importance to a bank to manage its credit risks properly and to minimize its expected and unexpected losses.

Moreover, a good risk framework is vital to become compliant with the Basel II framework. The Basel II Internal Rating Based (IRB) approach requires banks to have an internal measure of credit risk, to determine the probability of default $(P D)$ of their counterparties. Most banks have difficulties in establishing credible and reliable estimates of the risk factors (Basel Committee on Banking Supervision, 2001). Because, there is prior to default no way to discriminate unambiguously between defaulting and non-defaulting firms during the next years (McQuown, 1993), at best a probabilistic assessment can be made.

We focus in this research on default prediction of small and medium-sized enterprises (SMEs). Many different modelling techniques exist to estimate the $P D$. Most of these models use public market data, and can, as a consequence, only be used for large (quoted) companies. The body of research on (private) SME loans credit risk and $P D$ estimation is sparse, although SME exposures are a relatively high share of bank loan portfolios. This lack of data makes SMEs an interesting topic to study, but it also has made it one of the most difficult fields to conduct empirical research until recently.

Small firms are an engine of growth in many countries. A significant portion of the employment growth in the U.S. is credited to small firms. And small firms are apparently even more important in Europe (Degryse and Van Cayseele, 2000). In industrialized countries small and medium-sized enterprises (SMEs) account for more than $90 \%$ of all firms, employ about two-thirds of the workforce, and contribute to nearly $50 \%$ of value added in non-agricultural production (Baas and Schrooten, 2005). Since small firms depend largely on banks for their external finance because they have limited or no access to the capital market, the impact of various aspects of the bank-borrower relationship on the terms of the loan contract is a topic worth researching (Degryse and Van Cayseele, 2000). Without efficient bank lending, the development of SMEs will be hindered materially.

Different kinds of obligors require different rating $(P D)$ models. From a credit risk point of view, SMEs are different from large corporates, since they have severe agency problems. Managerial 
ownership is common for SMEs which causes market frictions such as information asymmetry and agency costs. SME business is riskier than large corporate lending (Altman and Sabato, 2007). This negatively influences loan availability and credit terms. Accounting quality is in general lower for SMEs, and private firms exhibit higher levels of earnings management (Burgstahler, Hail and Leuz, 2006). Small firms are informationally opaque (Peterson, 1999) and can therefore not credibly convey their quality. However, since SMEs play such a central role in market economies, it is very important for banks to have credit risk models that are able to provide a reliable prediction of default. Failure to correctly reflect the risk profile of SMEs will lead to inefficient resource allocation decisions. As a consequence, banks should develop credit risk models specifically addressed to SMEs, in order to minimize its expected and unexpected losses.

Other research on SMEs credit risk includes work by Edminster (1972), Laitinen (1992), Moody's RiskCalc ${ }^{\mathrm{TM}}$ (Falkenstein, Boral and Carty, 2000), Dietsch and Petey (2002), Allen, DeLong and Saunders (2004) and Altman and Sabato (2007).

There are three main approaches to credit risk modelling: the structural form model approach, reduced form or intensity models, and the traditional models. For privately held firms with no market data available, accounting-based traditional credit scoring models are the most common approach. This approach is used by Edminster (1972), Altman and Sabato, (2007), and Moody's RiskCalc ${ }^{\mathrm{TM}}$ (2000). Although these scoring models have well known disadvantages, it remains the most effective and widely used methodology for the prediction of default of private companies. The main disadvantages are the fact that ratios might correlate with each other which affects the results, and when using comparative ratio analyses, one must recognize differences between firms, for example use of different methods of accounting or methods of operations (Stickney and Weil, 1997).

The goal of this research is to develop a $P D$ model for SMEs, using the structural form model approach, and to test the applicability in practice. Our approach is closest to a study by Liao and Chen (2005). The basic principle of a structural form model is that a company is in default when the asset value of the company falls below the default boundary, since in that case the assets are insufficient to repay the liabilities; the market net worth reaches zero. Since this principle in general applies to all firms, we might overcome some of the issues related to traditional credit scoring models.

This paper has two other motivations. The first is to provide an 
overview of the characteristics of SMEs. The second is to work out a list of characteristics that a $P D$ model for SMEs should contain, based on these SME characteristics. SMEs have specific peculiarities that influence the modelling of credit risk. SMEs are informationally opaque, have volatile financial statements, and the relatively small size of each loan implies that since lenders face fixed costs in lending, lending to small firms is by definition more expensive. The SME characteristics are taken into account in the model development phase.

In this research, the structural form SME PD model is developed and tested on a unique dataset on private firm's bank loans of a Dutch bank. The analysis is carried out on financial statement data of a sample of 1,238 Dutch firms. The sample contains 998 non-defaulted and 240 defaulted companies, where default is defined as 90 days past due (Basel II definition). This research differs from most research done on this topic because usually, bankruptcy is used as a definition of failure. Since there is often a great time leap between the deposit of the last published account and the moment of bankruptcy, especially in case of SMEs, using bankruptcy as criterion leads to low data availability and quality. We have chosen ' 90 days past due', to overcome this data problem, to be Basel II compliant and to reflect the banking practice.

The results of the structural form model are promising: the model output differs significantly between defaulted and non-defaulted firms and about $63.8 \%$ of the companies are predicted correctly out-of-sample as a defaulted or non-defaulted company using the structural form model. The structural form measure can be used on its own, or as an additional variable in a credit risk model. To test the out-of-sample significance of the structural form measure in default prediction, compared to popular financial ratios, a second $P D$ model is generated using logistic regression. The results indicate that the structural form model variable is significant in default prediction of SMEs and that this variable has some additional predictive power, next to the significant financial ratios (profitability, solvency and size). Overall, the results indicate that the structural form model is a good indicator of default of SMEs that can be used on its own, or as an additional variable in a credit risk model.

The results of this study contribute to enhancing our understanding of credit risk modelling of SMEs and the application of structural form models for SMEs.

The remainder of this paper is structured as follows. In the next section credit risk is discussed. In section III, SMEs and the characteristics of credit risk models for SMEs are described. Then, the 
research method (IV) and the data and results (V) are presented. In section VI, the validation and the applicability of the methodology is worked out. The paper ends with a summary and some concluding remarks (VII).

\section{Credit Risk}

\section{A. Probability of Default}

Credit risk consists of three main components, the probability of default $(P D)$, exposure at default (EAD) and the recovery rate (RR) or loss given default (LGD). Each of these items is critical for determining credit risk. The focus of this research is on the $P D$ : the probability of a default during a given period of time (assessment period). Default means not receiving timely interest and principal as specified in the debt agreement. The $P D$ is most important, but also most difficult to determine. Prior to default, there is no way to discriminate unambiguously between defaulting and non-defaulting firms during the next years (McQuown, 1993). At best a probabilistic assessment of the probability of default can be made.

Under the revised Basel framework, the IRB approaches require banks to estimate the $P D$ of all their counterparties. Basel II uses the following definition for the probability of default: 'The $P D$ is the probability that a borrower meets the default definition within one year, expressed as a percentage. A default is considered to have occurred with regard to a particular obligor when either or both of the following events have taken place (Basel Committee on Banking Supervision, 2006): the obligor is 90 days past due on any material credit obligation; and the obligor is unlikely to pay its credit obligations'.

\section{B. Credit Risk Models}

To measure credit risk $(P D)$ on individual bank loans, banks use credit risk models. Credit risk models lead to a faster lending process; therefore, lending volume can increase. Banks that use these models appear to be more productive at lower costs (Allen et al., 2004).

Different kinds of obligors require different rating models due to their specific peculiarities that influence the modelling of credit risk. As a consequence, in order to minimize their (un)expected losses, banks should develop credit risk models specifically addressed to SMEs. 
To measure the $P D$, several methodologies or techniques can be used: the structural form model approach (Merton, 1974; Black and Scholes, 1973); reduced form or intensity models (Jarrow and Turnbull, 1995); and traditional methods (Altman, 1968; Taffler, 1982; Back, Laitinen, Sere and Van Wezel, 1996).

Under the first approach, the structural form model approach, a credit facility is regarded as a contingent claim on the value of a firm's assets. The assets of a firm are valued according to option pricing theory (Black \& Scholes, 1973; Merton, 1974). Structural form models can therefore only be used for firms with traded equity and/or debt. Default occurs when the estimated value of a firm hits a pre-specified default threshold. Recent developments include Brownian Excursions and Parisian Barrier Options (Schröder, 2003).

Intensity-based models, also known as hazard rate or reduced-form models focus directly on the modelling of the $P D$. The intensity-based approach defines the time of default as the first jump of an exogenously given jump process. As a consequence, a central role is played by the jumps intensity rate. The parameters governing the default hazard rate are inferred from market data. Reduced form models were originally introduced by Jarrow and Turnbull $(1992,1995)$ and subsequently studied by Duffie and Singleton (1999), who developed a basic affine model, which allows for jumps in the hazard dynamics.

The third approach contains the traditional methods. These include: expert systems, neural networks and multivariate credit scoring models, such as the linear probability model, the logit model (Ohlson, 1980), the probit model (Back et al., 1996) and the multiple discriminant model (Altman, 1968; Taffler, 1982).

For privately held firms with no market data available, accounting-based traditional credit scoring models are the most common approach. Although these scoring models have well known disadvantages, it remains the most effective and widely used methodology for the prediction of default for private companies. The main disadvantages are as follows. First, financial ratios are constructed from a number of components. It is possible that ratios of default and non-default companies do not show differences, while the components clearly differ (Beaver, 1966). This might for example be the case for the return on equity ratio where both the numerator and the denominator can be negative, leading to a positive ROE. Secondly, changes in ratios correlate with each other, which might deteriorate the results. And when using comparative ratio analyses, one must recognize differences between firms (for example use of different methods of accounting, 
types of financing, methods of operations, or seasonal or cyclical activities) (Stickney and Weil, 1997).

We focus in this research on the applicability of structural form credit risk models for SMEs. A lot of research is done on structural form models; however, there is only limited attention for the application of this type of model for private SMEs. The structural form model approach is worked out in more detail in section IV.

\section{Small and Medium-Sized Enterprises (SMEs)}

\section{A. Introduction on SMEs}

Financial institutions and banks have built many statistical models to measure the risk of their loan portfolio. However, no single type of model is suitable across all portfolios. Few attempts have been devoted to small commercial loans credit risk, although SME exposures are a relatively high share of bank loan portfolios, especially in Europe. For OECD (Organisation for Economic Co-operation and Development) members, the percentage of SMEs out of the total number of firms is greater than 97\% (Altman and Sabato, 2007).

The definition of the business sizes: micro, small, medium, or large, results from the application of different criteria, such as the number of employees, the sales volume or the total assets. According to the guidelines of the European Commission (2001), the following subdivision can be made (see table 1).

\section{B. Characteristics of SMEs}

SME exposures have specific peculiarities. Several factors distinguish credit risk in small (SME) from large (corporate) commercial loan portfolios.

\section{Information}

The most important characteristic defining small business finance is informational opacity (Peterson, 1999). There is far less information, both in number of years and in amount of information, on SMEs. Small firms do not enter into contracts that are publicly visible or widely reported in the press. Contracts with suppliers and customers are generally kept private. In addition, small businesses do not issue traded 
TABLE 1. The subdivision of business size

\begin{tabular}{llll}
\hline $\begin{array}{c}\text { Business } \\
\text { size }\end{array}$ & $\begin{array}{l}\text { Number of } \\
\text { employees }\end{array}$ & \multicolumn{1}{c}{$\begin{array}{c}\text { Annual } \\
\text { turnover }\end{array}$} & \multicolumn{1}{c}{$\begin{array}{c}\text { Total } \\
\text { assets }\end{array}$} \\
\hline Large & $>250$ & $>€ 50 \mathrm{mln}$ & $>€ 43 \mathrm{mln}$ \\
Medium & $>50-<250$ & $>€ 10-<€ 50 \mathrm{mln}$ & $>€ 10-<€ 43 \mathrm{mln}$ \\
Small & $>10-<50$ & $>€ 2-<€ 10 \mathrm{mln}$ & $>€ 2-<€ 10 \mathrm{mln}$ \\
Micro & $<10$ & $<€ 2 \mathrm{mln}$ & $<€ 2 \mathrm{mln}$ \\
\hline SME & $<250$ & $<€ 50 \mathrm{mln}$ & $<€ 43 \mathrm{mln}$ \\
\hline
\end{tabular}

securities that are continually priced in public markets (Allen et al., 2004). There is often an absence of separation between owner and management, which can result in an intermingling of personal expenses with business expenses and a failure to discriminate between management salary and dividends (Damodaran, 2002).

Accounting data appears only at discrete intervals, for SMEs in most cases on a yearly basis. Accounting quality is in general lower for SMEs and private firms exhibit higher levels of earnings management (Burgstahler et al., 2006). Private SMEs operate under far looser accounting standards than most publicly traded firms. Many of the smallest firms do not have audited financial statements. As a result, small firms often cannot credibly convey their quality (Berger and Udell, 1998).

The financial statement data of SMEs are occasionally extremely volatile from year to year due to changes in economic conditions, corporate acquisitions, changes in product lines or geographic markets served, a management buy-out, or any other specific event. SMEs have often been around for much shorter time periods than most publicly traded firms, resulting in less historical information available on them (Damodaran, 2002). In some cases, SMEs have only one year of (representative) financial statement data available.

On the contrary, the large corporate loan portfolio uses rich information concerning the financial situation of clients. This information comes from rating agencies and financial markets. In general, the information is available in time series, which allows trend analysis.

Most $P D$ models use market information, as bond or equity prices or credit default swap data. This kind of information is not available for SMEs. These data limitations restrict the modelling choices. 
Economy

SMEs are more sensitive to business cycles (Rijken, 2005). They are expected to be more likely to fail, because they (1) are less likely to benefit from scale effects, (2) have less power in negotiations with financial and social partners, (3) are less likely to benefit from their experience or 'learning effects,' compared to large firms, and (4) often operate in small markets, due to size effects.

Because of the lack of product and market diversification and the fact that SMEs have in general a low(er) number of suppliers and consumers, SMEs face high uncertainty about their future cash flow levels and timing. This leads to volatile financial statement data through time (Rijken, 2005).

The need to have financing available in order to seize unexpected market opportunities or to react to external shocks is particularly important for the vitality of SMEs (Rivaud-Danset, Dubocage and Salais, 1998). Flexibility is important because a company must be able to take advantage of customers' needs and also because in their day-to-day activity SMEs meet uncertainty and need to react quickly to unexpected events or opportunities. A credit risk model should therefore be able to determine the $P D$ within a short period of time.

\section{Costs}

The relatively small size of each loan of a small commercial loan portfolio implies that the absolute size of the credit risk on any individual loan is minimal. Losses on any single loan will not cause the bank to become insolvent (Allen et al., 2004). The cost per loan of determining the credit risk is often greater than the benefit in terms of loss avoidance, because it is time consuming and expensive to extensively evaluate a loan at its individual level (Dietsch and Petey, 2002). Since lenders face fixed costs in lending, lending to small firms is by definition more expensive per dollar lent (Peterson, 1999). Therefore, methodological choices are restricted by time and cost constraints.

\section{Variation}

There is a large variation in the legal structure (Bhatia, 2006) and in the activities of SMEs. It is therefore difficult to attain homogeneity with small businesses as the size of the exposures, types of industry and the 
legal structure of obligors all vary substantially. It is however not possible, especially for smaller banks, to develop different credit risk models for each type of SME, due to financial constraints. A PD model should therefore be broadly applicable.

\section{Characteristics of an SME PD Model}

Because of the SME characteristics described above, it is more difficult to develop an accurate $P D$ model for SMEs, than for larger corporates. The use of possible credit risk models or techniques and input variables is limited. Models developed for larger firms cannot be used for SMEs without adjustment. Default models based on public firm data and applied to (smaller) private firms will likely misrepresent actual default risk.

Besides the general credit risk model characteristics such as: accurate, statistically robust, reliable, intuitive, and transparent, a $P D$ model for SMEs should have the following features: time and cost efficient; make use of the limited financial data available for SMEs; able to work with one year of financial data (in case only one year of (reliable) data is available); and broadly applicable.

The goal of this research is to develop a structural form $P D$ model for SMEs that meets these characteristics and to test the applicability in practice.

\section{Research Method}

\section{A. The Structural Form Model Approach}

Figure 1 shows the structural form model approach, which is the starting point of this research. Structural form models focus on constructing the distribution of a firm's asset value and estimating the $P D$. A firm's asset value is derived from the equity market value through an option-based theory (Black and Scholes, 1973; Merton, 1974). These models assume that the value of the firm's activities (asset value) moves through time with a given expected return and volatility. Debt is seen as a bond and has a senior claim on the firm's cash flows and assets. The default risk of a firm increases when the asset value approaches the default boundary, which is based on the firm's liabilities. When the asset value of a company falls below the specified default boundary, the company is in default, since the assets are insufficient to repay the liabilities; the 


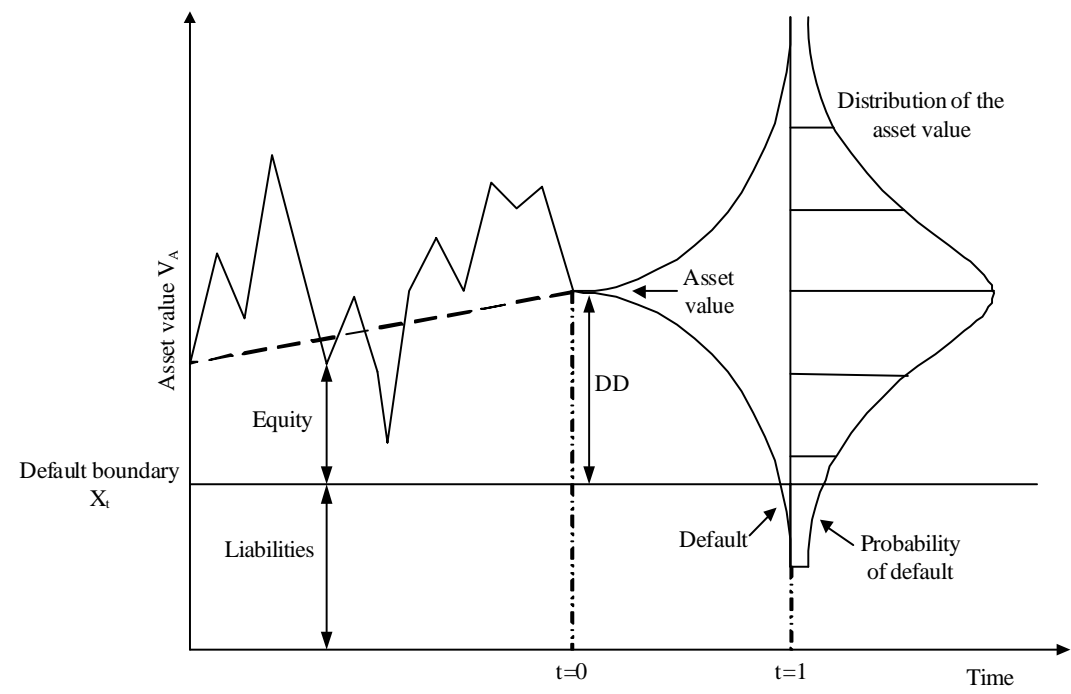

FIGURE 1.- The structural form model approach

market net worth reaches zero. The probability of default is the probability of the asset value to fall below default boundary.

Default happens if and only if, at time $t$, the value of the firm's assets $V_{A}$ is lower than its default boundary $X_{t}$ (see figure 1 ).

$$
P D=p\left[V_{A}<X_{t}\right]
$$

For a firm to enter the default region, the market value of assets $V A$ has to drop by $V_{A}-X_{t}$ or the distance to default $(D D)$ number of standard deviations, during the next year. The $D D$ is a measure of default risk and can be stated as (Crosby and Bohn, 2003):

$$
D D=\frac{\ln \frac{V_{A}}{X_{t}}+\left(\mu-\frac{\sigma_{A}^{2}}{2}\right) T}{\sigma_{A} T}
$$

$\sigma_{A}: \quad$ Asset volatility

$\mu: \quad$ Expected return on assets

$T: \quad$ Assessment period

ln: Natural logarithm 
In the $D D$, the main three elements that determine the $P D$ are combined (Crosby and Bohn, 2003): the asset value, the default boundary, and asset risk. The $D D$ indicates how many standard deviations the firm is away from default and can be converted into a $P D$. The smaller the $D D$, the more likely a default is to occur.

\section{B. Calculation of the Probability of Default}

The probability of default can be derived in three steps: estimation of the input variables; calculation of the distance to default as a measure of default risk; and scaling of the distance to default to the probability of default.

There are six input variables needed to be able to determine the PD of an individual company: assessment period $(T)$, current market value of assets $\left(V_{A}\right)$, volatility of assets over the assessment period $\left(\sigma_{A}\right)$, default boundary $\left(X_{t}\right)$, expected return on assets $(\mu)$, and distribution of assets. Number one to five are required to calculate the $D D$. Number six is used to convert the $D D$ into a $P D$.

\section{Assessment Period}

According to Basel II, the $P D$ is the probability that a borrower meets the default definition within one year, expressed as a percentage. Therefore, the assessment period chosen is one year.

\section{Current Market Value of Assets}

When using a structural form model, the firm's asset value is generally derived from equity market data through an option-based model (Black and Scholes, 1973). For SMEs, this is not possible, due to the lack of market data, as described in section III. There are several ways to determine the market value of an SME, a.o. (Saunders and Allen, 2002; Palepu, Healy and Bernard, 2004): KMV's private firm model, based on the average equity multiple; discounted dividends (the present value of expected future dividends); and the discounted free cash flow $(F C F)$ approach.

Because of a lack of data, the first two methods are rejected. Several SMEs do not pay dividends. For KMV's private firm model, the industry average market value of equity is needed. This type of information of SMEs is scarce and industry average variables vary considerably over time (Åstebro and Winter, 2002). Since the net 
present value methodology of cash flows is widely agreed to be the superior method for valuing a company (Weston, Siu and Johnson, 2001; Damodaran, 2002), this method is chosen.

$F C F$ measures a firm's cash flow remaining after all expenditures required for ongoing activities, like buildings, equipment, and furnishings, and growth have been paid off. Cash flows are critical to assessing a company's liquidity and creditworthiness. Companies with projected operating cash flows that comfortably exceed debt principal and interest payments are deemed low credit risks. Growing FCFs are frequently a prelude to increased earnings. By contrast, shrinking $F C F$ s signal trouble ahead. It is important to note that a negative $F C F$ is not always bad in itself. If $F C F$ is negative, it could be a sign that a company is making large investments. If these investments earn a high return, the strategy has the potential to pay off in the long run. However, on the short-run, default risk is higher. There is no unique definition of $F C F$ in literature. In this research, the following definition is used (Copeland, 2000):

$$
F C F_{t}=\text { Operating Cash Flow }_{t}-\text { Capital Expenditures }_{t}
$$

Where: Capital expenditures $=$ expenditures for capital leases + increase in funds for construction + reclassification of inventory to property, plant, and equipment

There are several models to determine the present value of future cash flows, for example models that assume that $F C F$ follow a growth pattern and grow at a constant growth rate $g$ (Gordon's growth model). Since, in case of SMEs the growth rate will vary significantly year by year, and difficulties of SMEs in accessing external finance to finance good investment opportunities, limit their growth (Fagiolo and Luzzi, 2006), we expect the assumption of a constant growth rate to be often violated. Therefore a model without a growth factor is used to determine $V_{A}$.

$$
\begin{gathered}
V_{A}=F C F \sum_{t=1}^{n} \frac{1}{(1+W A C C)^{t}} \\
\lim _{n \rightarrow \infty} V_{A}=\frac{F C F}{W A C C}
\end{gathered}
$$

The calculation of the weighted average cost of capital (WACC) for 
SMEs is complex; because some variables like the cost of equity value and the systematic risk factor, coming from market information for traded companies, need to be estimated. There are some alternative approaches available to determine the WACC for private firms (Damodaran, 2002), however, these require complex analyses and are based on assumptions that are not met in practice, which significantly affects the results (Petersen, Plenborg and Schøler, 2006). Foster (1986) suggests using the risk free rate $r_{f}$ instead of the $W A C C$ for valuation. In this research, we follow the advice of Foster, the asset value therefore equals:

$$
\lim _{n \rightarrow \infty} V_{A}=\frac{F C F}{r_{f}}
$$

As mentioned in paragraph III, $B$, the financial statement data of SMEs are occasionally extremely volatile. Extreme data volatility is defined as a total assets change of above $100 \%$ or below $-50 \%$ from one year to another. In some cases, only one year of financial statement data is available. For the model to be well applicable, it is important that the proposed $P D$ methodology is able to work with limited financial statement data. When $k$ years of representative $V_{A}$ data are available, with a maximum of four, these can be used to calculate the average value of assets $V_{A, \text { avg }}$, to give a more precise indication of $V_{A}, k$ is limited to a maximum of four years of historical data, because older data are less representative for the current situation. $V_{A, \text { avg }}$ is used to calculate the $D D$ according to formula 2 . We give more weight to the last year(s) of data to reflect that these data are more recent and therefore more relevant, according to the following equation:

$$
V_{A, \text { avg }}=\frac{\sum_{i=1}^{k} i V_{A, t(k-i)}}{\sum_{i=1}^{k} i}
$$

where $k$ is the number of years of data available, with $k \in\{1,2,3,4\}$.

Volatility of Assets Over the Assessment Period

Asset risk is measured by the asset volatility, which is usually defined 
as the standard deviation of the annual percentage change in asset value of the company that is rated. SMEs occasionally have only one or a few years of financial statement data available and the asset volatility is sometimes extremely high (above $+100 \%$ or below $-50 \%$ ). In these cases, the asset volatility of the company itself does not give a good indication of asset risk, because it is based on outliers and/or a few observations. In case there is only one year of data available, the asset volatility cannot be computed. In order to overcome these issues, not the asset volatility of the company itself is used, but the average asset volatility of a larger sample of SMEs.

\section{Default Boundary}

There are two types of structural form models that have been quite widely used in academic and practical applications. First, those with an 'exogenous default boundary' that reflects only the principal value of debt (Merton, 1974; Longstaff and Schwartz, 1995). Second, those with an 'endogenous default boundary' where default is chosen by management to maximize equity value (Black and Cox, 1976; Leland, 2004). This default boundary is determined not only by debt principal, but also by the riskiness of the firm's activities, the maturity of the debt issued, the payout levels, the default or bankruptcy costs and the corporate tax rates.

Since the endogenous default boundary is quite complex to determine for SMEs because of the determinants, we have chosen for the exogenous default boundary. Huang and Huang (2002) argue that it is reasonable to specify a default boundary $\left(X_{t}\right)$ that is some fraction $\beta$ (with $\beta \leq 1$ ) of debt principal, because firms often continue to operate with negative net worth. The long-term nature of some of the liabilities provides some breathing space. Crosbie and Bohn (2003) have found that the point of default generally lies somewhere between total liabilities and short-term liabilities; they use $\beta=0.5$.

The assessment period chosen is one year and since short-term liabilities are due within one year, total short-term liabilities are included in the default boundary. A portion $\beta$ of long-term liabilities is included in the default boundary, because of the interest and instalment payments that have to be made (Leland, 2004).

$$
X_{t}=L_{s}+\beta L_{l}
$$

with $L_{s}$ the short-term liabilities and $L_{l}$ the long-term liabilities. 
Expected Return on Assets

The expected return on assets $\mu$ will be based on the return on assets (ROA) ratio. The $R O A$ is a common measure that shows how profitable a company's assets $V_{A}$ are in generating revenue (net income: $N I$ ). Since SMEs occasionally have limited financial statement data available and the return on assets ratio sometimes contains extreme values, not the $R O A$ of the company itself is used, but the average return on assets of a larger sample of SMEs (comparable to the calculation of the volatility of assets). ROA can be computed as (Stolowy and Lebas, 2002):

$$
R O A=\frac{N I_{t-1}}{\frac{1}{2}\left(V_{A, t}+V_{A, t-1}\right)}
$$

\section{Distribution of Assets}

The $P D$ can be determined based on the $D D$ if the probability distribution of assets is known, or if the default rate for a given level of $D D$ is known. For SMEs, neither of the two is known. In the remainder of this paper, we therefore use the $D D$ as indicator of default. The distance to default indicates how many standard deviations the firm is away from default. The smaller the $D D$, the more likely a default is to occur.

\section{Data and Analysis (a test on the Dutch Market)}

\section{A. Sample}

The model described above is tested on a unique dataset on private firm's bank loans of a Dutch bank. The sample contains 240 observed defaulted and 998 observed non-defaulted SMEs. All SMEs of the bank that had a complete dataset available of at least one year of financial statement data in the period 1996 - 2007 are included in the sample. An SME is defined as having total assets of less than $€ 43 \mathrm{mln}$. The other two criteria of table 1 (number of employees and annual turnover) are left out of consideration. The default definition of Basel II is used: it classifies a company as default if a company misses principal and/or interest payments for more than 90 days. This research differs from 
TABLE 2. Total sample default and non-default

\begin{tabular}{|c|c|c|c|c|c|c|c|c|}
\hline & \multicolumn{4}{|c|}{ Non-default } & \multicolumn{4}{|c|}{ Default } \\
\hline & Total & Micro & Small & Medium & Total & Micro & Small & Medium \\
\hline Total & 998 & 508 & 365 & 125 & 240 & 107 & 102 & 31 \\
\hline Trade & 391 & 183 & 156 & 52 & 79 & 33 & 32 & 14 \\
\hline Service & 360 & 213 & 111 & 36 & 81 & 42 & 31 & 8 \\
\hline Manufacturing & 247 & 112 & 98 & 37 & 80 & 32 & 39 & 9 \\
\hline
\end{tabular}

most research done on this topic, because typically, default means a bankruptcy filing or liquidation. Although the use of the legal definition of bankruptcy is widely accepted, it also causes some problems, because the moment of legal failure does not reflect the real failure event. There is often a great time leap between the deposit of the last published account and the moment of bankruptcy, which leads to low data availability and quality. We have chosen to use ' 90 days past due', to overcome this data problem and to be Basel II compliant, and to reflect the banking practice.

Financial institutions, insurance companies, real estate companies, and public institutions are excluded from the analysis, due to the specificity of their financial statements. The sample does not contain newly founded firms. Companies traded on the stock exchange are excluded, because the relationship between financial variables and default risk varies substantially between traded and non-traded firms (Falkenstein et al., 2000). Very small SMEs $(<€ 100,000$ balance sheet total) are excluded, because their profile is not representative for the Dutch SME portfolio. Financial statements covering a period of less than twelve months are excluded. The time period used for the sample selection is 1996-2007. The accounting standards are Dutch accounting principles. It is assumed that the financial statements give a representative presentation of the financial situation of a firm. The $D D$ is calculated according to the formulas 2, 6, 7, 8 and 9.

Extreme data volatility is defined as a total balance sheet change of more than $100 \%$ or $-50 \%$. In case of extremely volatile data, only the latest year(s) of data are included in the analyses. In the rare occasion the predicted asset value $V_{A, \text { avg }}$ is negative, $\ln \left(V_{A, \text { avg }} / X_{t}\right)$, and therefore the $D D$ cannot be computed. In case $V_{A \text {, avg }}<X_{t}$, the $D D$ becomes negative. Therefore, in all cases where $V_{A \text {, avg }}<X_{t}$, which indicates default, the $D D$ is set equal to 0 .

The financial statement data of the year prior to default are used as a basis for the analysis, because the assessment period chosen is one 
TABLE 3. Development sample default and non-default

\begin{tabular}{|c|c|c|c|c|c|c|c|c|}
\hline & \multicolumn{4}{|c|}{ Non-default } & \multicolumn{4}{|c|}{ Default } \\
\hline & Total & Micro & Small & Medium & Total & Micro & Small & Medium \\
\hline Total & 748 & 381 & 273 & 94 & 180 & 81 & 76 & 23 \\
\hline Trade & 293 & 137 & 117 & 39 & 59 & 25 & 24 & 10 \\
\hline Service & 270 & 160 & 83 & 27 & 61 & 32 & 23 & 6 \\
\hline Manufacturing & 185 & 84 & 73 & 28 & 60 & 24 & 29 & 7 \\
\hline
\end{tabular}

TABLE 4. Holdout sample default and non-default

\begin{tabular}{|c|c|c|c|c|c|c|c|c|}
\hline & \multicolumn{4}{|c|}{ Non-default } & \multicolumn{4}{|c|}{ Default } \\
\hline & Total & Micro & Small & Medium & Total & Micro & Small & Medium \\
\hline Total & 250 & 127 & 92 & 31 & 60 & 26 & 26 & 8 \\
\hline Trade & 98 & 46 & 39 & 13 & 20 & 8 & 8 & 4 \\
\hline Service & 90 & 53 & 28 & 9 & 20 & 10 & 8 & 2 \\
\hline Manufacturing & 62 & 28 & 25 & 9 & 20 & 8 & 10 & 2 \\
\hline
\end{tabular}

year. The application of the default definition to an arbitrarily chosen year or time period involves a certain 'selection bias' (Shumway, 1999). It is clear that when the failure definition is applied to a certain arbitrarily chosen year or time period, the separation of companies into a failing and a non-failing population is artificial. The two populations will only be mutually exclusive within the chosen time period (Altman, Haldeman, and Narayanan, 1977). A company that meets the default definition shortly after the considered time frame is included in the non-default sample, but may already contain several characteristics of the default sample. Using an extended time frame solves this selection bias. In this research, we use an extended time frame for the non-default sample. The non-default sample only consists of companies that did not meet the definition of failure up to one year after the considered time period.

The total sample consists of 1,238 companies, 998 non-defaulted and 240 defaulted companies. The sample is at random divided over a development sample (75\%, 748 non-defaults and 180 defaults) and a holdout sample $(25 \%, 250$ non-defaults and 60 defaults) using a stratified sampling technique (Cooper and Schindler, 2003), to make sure that all industries and company sizes are represented in both samples. 


\section{B. Analysis}

The following variables (based on the formulas 2, 6, 7, 8 and 9) are needed to be able calculate the DD of individual obligors: volatility of assets over the assessment period $\left(\sigma_{A}\right)$, the risk free rate $\left(r_{f}\right)$, expected return on assets $(\mu)$, default boundary $\left(X_{t}\right.$ and $\left.\beta\right)$, and the $D D$ cut-off point for default. The development sample is used to determine these variables, except for the risk free rate.

\section{Volatility of Assets Over the Assessment Period}

The average one year asset volatility $\sigma_{A}$ is determined based on all available annual asset volatilities of the development sample. In case a financial statement consists of more than 2 years of data, all the asset volatilities available of that company are included. This results in 1,351 cases. Extreme individual asset volatilities (above $+100 \%$ and below $-50 \%$ ) are excluded for the purpose of calculating the average asset volatility (93 cases). Table 5 indicates that there are differences in asset volatility between industries and company sizes and between default and non-default. Because the structural form model is used for both default and non-default SMEs, a weighted average asset volatility is used for determining the $D D$. The average annual default percentage over the period 1981-2006 equals $1.44 \%$ (Standard \& Poor's, 2007). A weighted average asset volatility of $16.69 \%(=98.56 \% \cdot 16.69 \%+$ $1.44 \% \cdot 16.06 \%)$ is applied for determining the $D D$.

\section{Risk Free Rate}

The return on ten years Dutch government bonds (risk free rate) is used as an indication for the $W A C C$ to calculate the market value of assets $V_{A}$, as described in section IV, $B$, (see table 6).

\section{Expected Return on Assets}

The average one year expected return on assets $\mu$ is determined based on all available annual ROAs of the SMEs in the development sample, in total 1,403 . Outliers (above $+100 \%$ and below $-100 \%$ ) are ignored (24 cases). Table 7 indicates that there are differences in return on assets between industries and company sizes. A weighted average expected return on assets of $8.38 \%(=98.56 \% \cdot 8.45 \%+1.44 \% \cdot$ $-3.78 \%$ ) is applied for the calculation of the $D D$. 


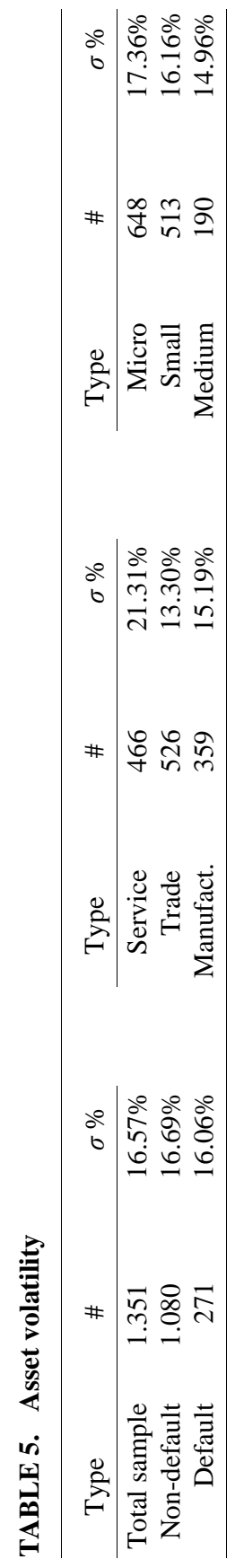




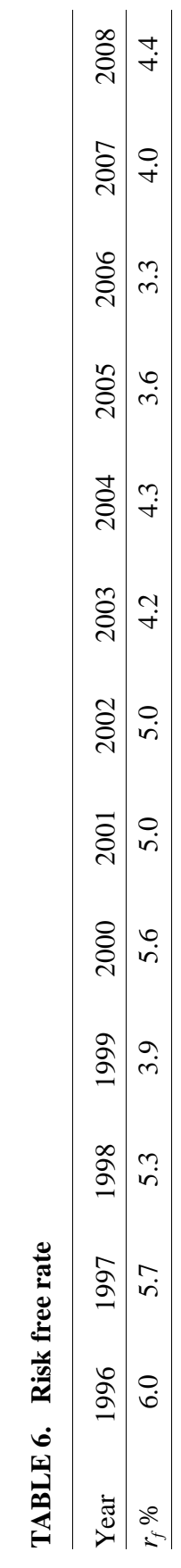




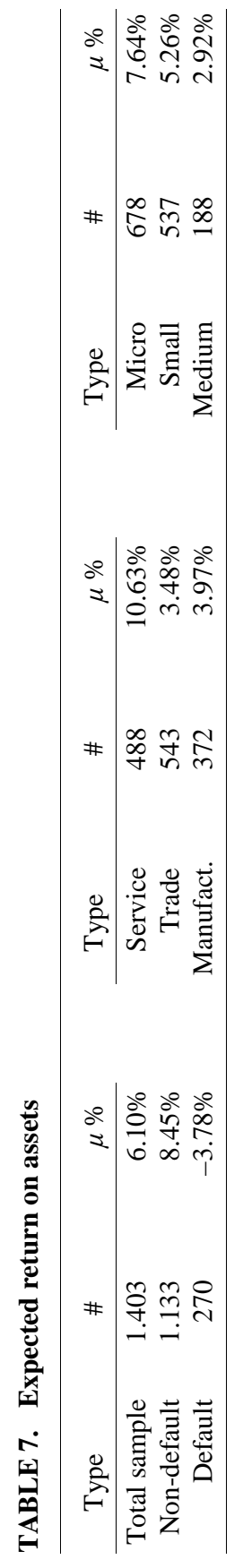




\section{Default Boundary and DD Cut-off Point for Default}

Two important values need to be decided on: the fraction $\beta$ of long-term liabilities that should be included in the default boundary $X_{t}$ and the $D D$ cut-off point for default.

In case the $D D$ is 0 , the company is technically bankrupt, not able to repay principal and interest in total. However, the default definition used is 90 days past due and it can be expected that a company is in default some time before technical bankrupt. It is therefore likely that the optimal $D D$ default cut-off point $>0$.

The default boundary $X_{t}$ and the $D D$ cut-off point are chosen, based on the development sample, by selecting this combination of values that minimizes the total misclassification percentage. There are two types of classification errors: a type I error means classifying a firm as not likely to default, when it actually does default, i.e. a false positive. A type II error means classifying a firm as likely to default when it does not default. In a type I error situation, a bank loses in the default, while in a type II error situation, the bank misses a good investment. Since the default boundary $X_{t}$ influences the level of the $D D$, the optimal values for $\beta$ and the $D D$ cut-off point are determined based on a combined analysis. For all SMEs in the development sample, the $D D$ is calculated using a $\beta$ of $0.0,0.25,0.5,0.75$ and 1.0 .

Tables 8 and 9 present the number and percentage of misclassification errors of both the non-default and default sample. The tables show that for the non-default sample the lower the beta and the lower the cut-off point, the lower the number of errors. For the default sample, the opposite holds. The underlined numbers indicate the combination of $\beta$ and $D D$ cut-off point that leads to the lowest misclassification percentages, assuming equal misclassification costs for type I and type II errors and equal proportions of defaulters and non-defaulters in the population. The optimal cut-off point is 4 with a $\beta$ of 0.25 . This results in an average misclassification percentage of $42.29 \%$.

A type I error (unexpected default) is in practice in most cases more costly than a type II error. However, since both types of errors create different types of economic costs for a bank and the optimum is bank specific, it is difficult to set an optimal general default cut-off point. This optimal point is based on: collateral (LGD) of a loan, bankruptcy costs, level of revenues on good investments, and the amount of capital a bank has available to grant credit. 


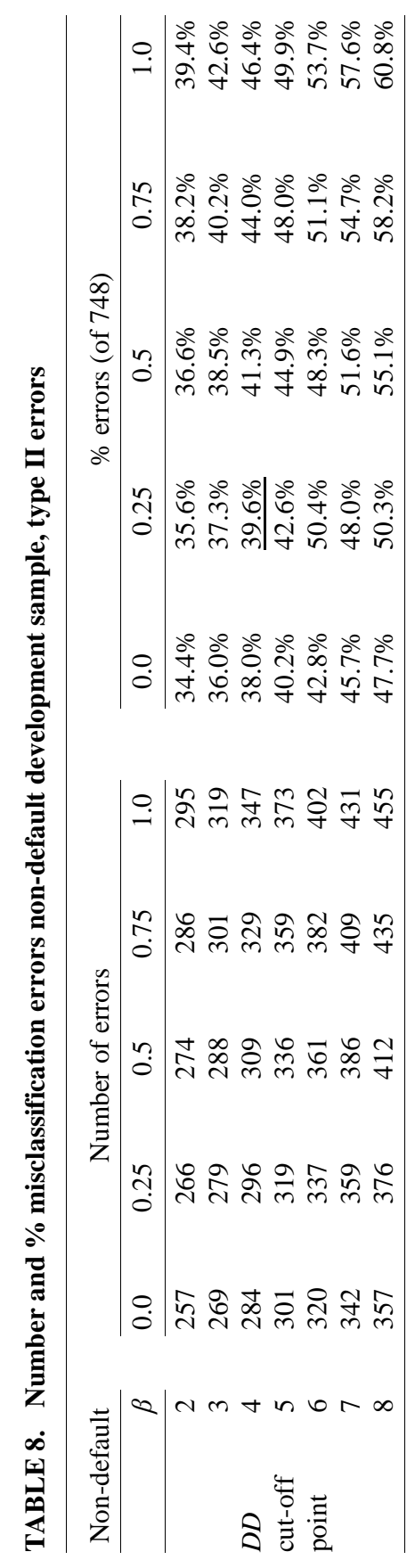




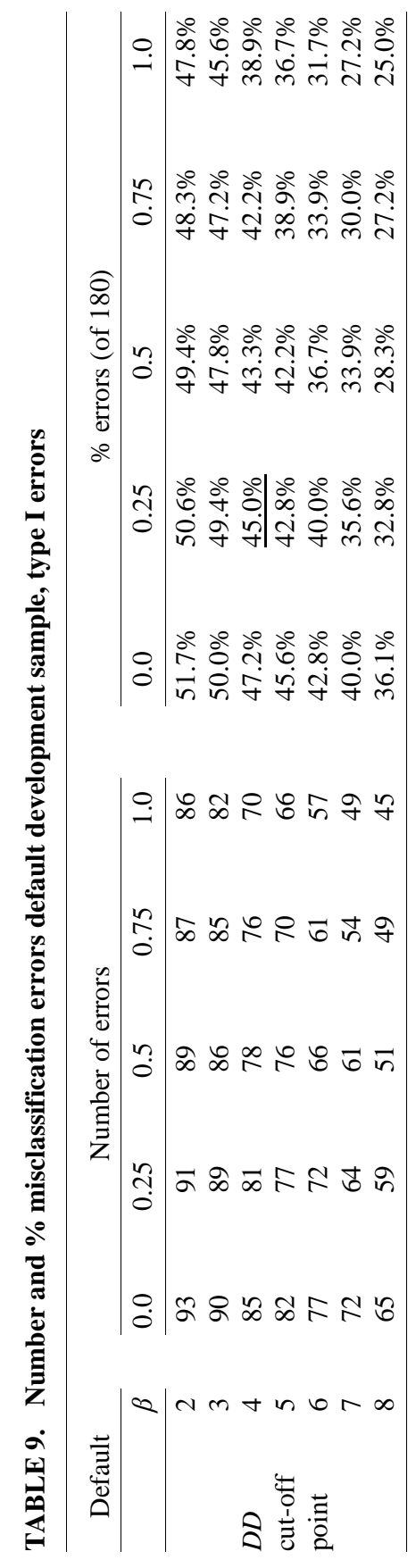




\section{Validation and Applicability of the Methodology}

\section{A. Validation}

The holdout sample is used to give an indication of the out-of-sample quality of the structural form model and to validate the model. The holdout sample consists of 60 defaulted companies and 250 non-defaulted companies. We have calculated the $D D$ for the holdout sample using $\beta=0.25, \sigma_{A}=16.69 \%$ and $\mu=8.38 \%$. The results are presented in table 10 and figure 2 .

The $D D$ of the default sample and non-default holdout sample differ significantly on a $99 \%$ confidence level. The $D D$ ranges for non-default from 0 to 32 and for default from 0 to 19.

Tables 11 and 12 present the number and percentage of misclassification errors of the holdout sample. The underlined numbers indicate the combination of $\beta$ and cut-off point that leads to the lowest number of total errors, assuming equal costs of type I and II errors and equal proportions of defaulters and non-defaulters.

The optimal combination for the development sample was a cut-off point of 4 and a $\beta$ of 0.25 . According to this combination, $63.8 \%$ of the holdout sample is correctly classified.

To out-of-sample validate the results of the structural form model; we use the receiver operating curve (ROC) and its summary index known as the area under the ROC curve (AUROC). This is one of the most popular validation techniques and because of its statistical properties; the AUROC provides a meaningful indication of the discriminatory power of a rating system (Basel II working paper No. 14, 2005).

To construct the ROC curve, the hit rate $H(C)$ which is the number of defaulters predicted correctly with the cut-off value $C$, and the false alarm rate $F A R(C)$, the number of non-defaulters that were classified incorrectly as defaulters by using the cut-off value $C$, need to be calculated. The ROC curve is a plot of $H R(C)$ versus $F A R(C)$. The ROC curve of the structural form model is presented in figure 3 .

To assess the out-of-sample discriminatory power of the structural form model, the area under the receiver operating curve (AUROC) is calculated (Sobehart, Keenan, and Stein, 2000). The larger the AUROC is, the better the model. An empirical approximation of the AUROC, denoted as $A$ is as follows:

$$
A=\frac{1}{2} \sum_{i=1}^{n}\left(F A R_{i}-F A R_{i-1}\right)\left(H R_{i}+H R_{i-1}\right)
$$


TABLE 10. The average $D D$ of the holdout sample

\begin{tabular}{ccc}
\hline Holdout sample & Number & Avg. $D D$ \\
\hline Total sample & 310 & 8.412 \\
Default & 60 & 4.730 \\
Non-default & 250 & 9.296 \\
\hline
\end{tabular}

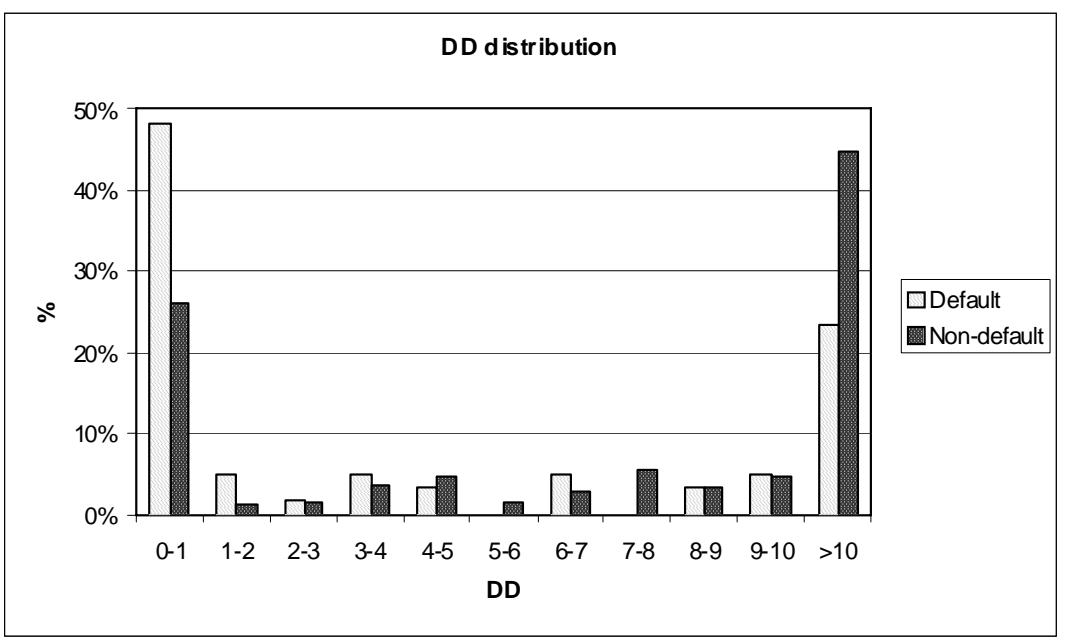

FIGURE 2.- The $D D$ distribution for default and non-default SMEs

with $F A R_{i}$ the false alarm rate with interval $i, H R_{i}$ the hit rate with interval $i$, and $n$ being the number of intervals chosen such that $F A R_{n}=1$.

The out-of-sample AUROC of the $D D$ variable with $\beta=0.25, \sigma_{A}=$ $16.69 \%$ and $\mu=8.38 \%$ is $57.01 \%$. The accounting ratio $V_{A, \text { avg }} / X_{t}$ is input for the $D D$ measure. To test the significance of the $D D$ measure, compared to the ratio $V_{A, \text { avg }} / X_{t}$, we also calculate the latter's AUROC. The out-of-sample AUROC for the ratio $V_{A \text {, avg }} / X_{t}$ with $\beta=0.25$ is $48.93 \%$. Engelmann, Hayden and Tasche (2003) argue that the AUROC is between 0.5 and 1 for any reasonable rating model in practice.

The results of this structural form model are promising. The model consists of one 'ratio' with only five components and it gives a first indication of the quality of an SME, for example when granting a loan. A low $D D$ is an indication that additional analyses might be needed. The accuracy ratios indicate that the structural form model outperforms the 


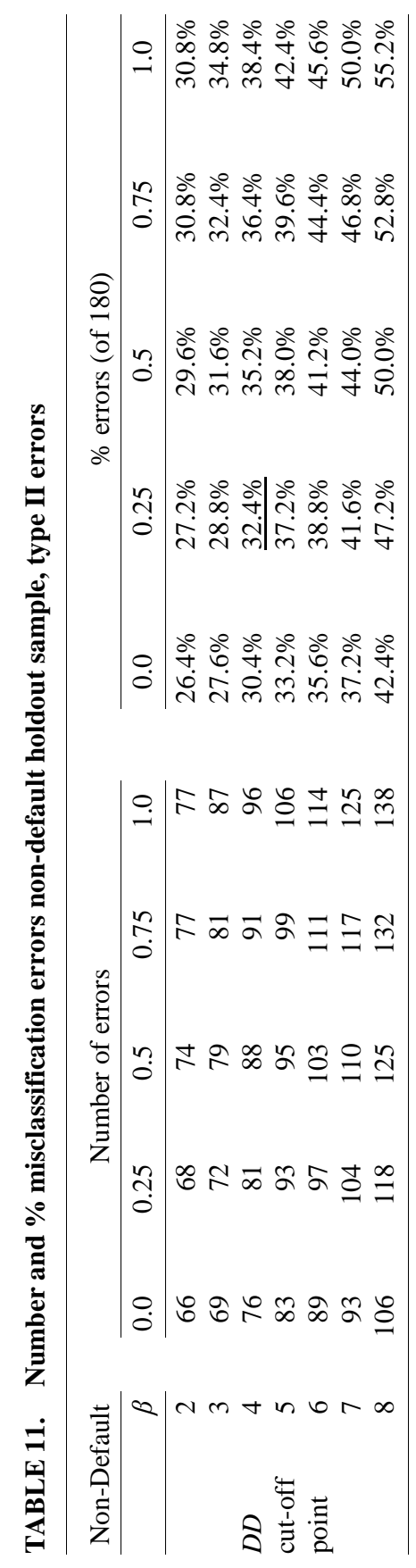




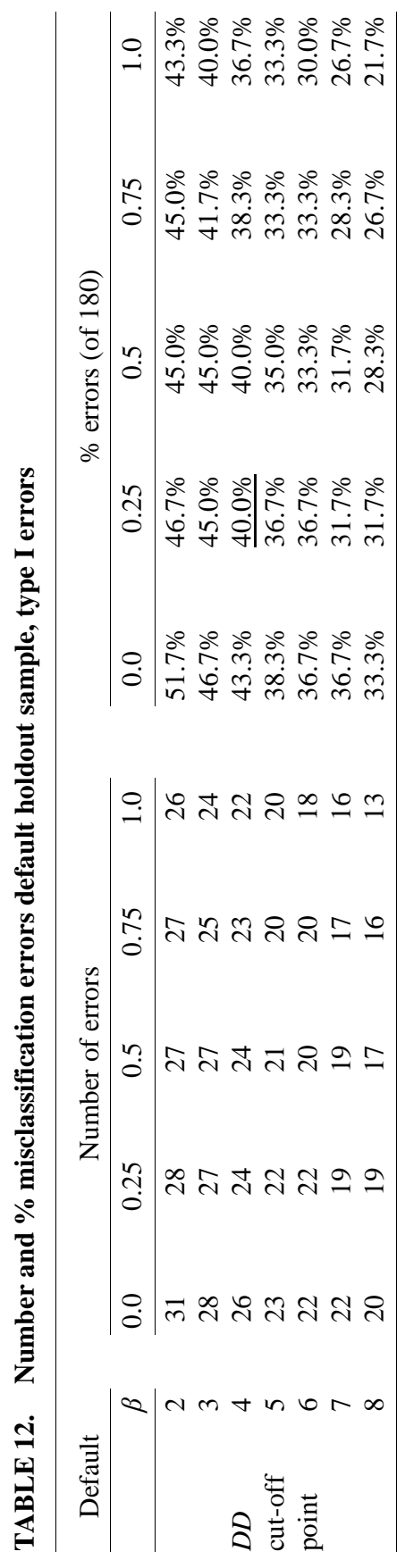




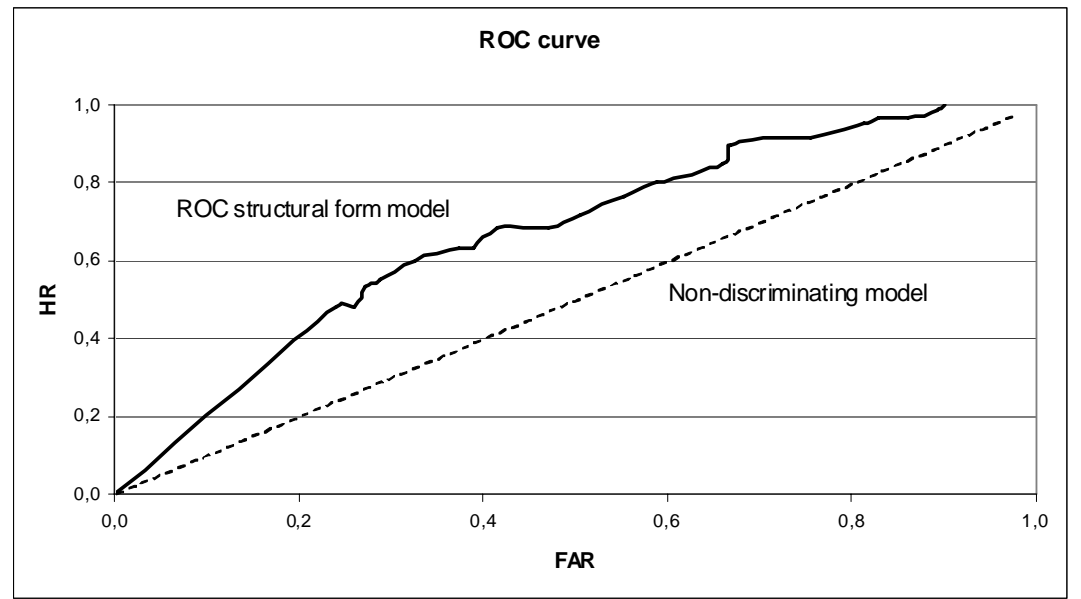

FIGURE 3.- ROC curve of the structural form model

accounting ratio $V_{A, \text { avg }} / X_{t}$. The $D D$ contains additional information, compared to the ratio $V_{A, \text { avg }} / X_{t}$ and has better predictive power.

\section{B. Validation Using Logistic Regression}

The structural form model, presented in this research, gives an indication of the credit risk of SMEs, and can be used on its own, or, for example, as an additional variable in a credit risk model. To test the out-of-sample significance of the $D D$ variable, compared to the financial ratios that are in general used in default prediction, two additional $P D$ models are generated using logistic regression, based on the holdout sample. We include seven variables: the distance to default $(D D)$, net income / total assets (NI/ TA, profitability), total liabilities / total assets (TL / TA, solvency), current assets / current liabilities (CA / CL, short-term liquidity), sales / total assets (Sales / TA, capital turnover), the natural logarithm of total assets ( $\ln T A$, size) and the market value of assets / liabilities ( $V_{A, \text { avg }} / X_{t}$, solvency). A $\beta=0.25, \sigma_{A}=16.69 \%$ and $\mu=8.38 \%$ are used for the $D D$ and $\beta=0.25$ for the ratio $V_{A, \text { avg }} / X_{t}$. The financial ratios are selected based on their performance in one of the previous studies, popularity, data availability (Hair, Black, Babin, Anderson and Tatham, 2006) and variables used in this research. The last variable is added to test the difference in predictive power between the $D D$ and the accounting ratio $V_{A, \text { avg }} / X_{t}$, because this ratio is input for 
TABLE 13. Regression output

\begin{tabular}{|c|c|c|c|c|c|c|}
\hline \multirow{3}{*}{$\#$} & \multirow[b]{2}{*}{ Variable } & \multirow[b]{2}{*}{ Direction } & \multicolumn{2}{|c|}{ Model A - incl. DD } & \multicolumn{2}{|c|}{ Model B - excl. DD } \\
\hline & & & Coeff. & p-value & Coeff. & p-value \\
\hline & Intercept & & 3.599 & 0.099 & 2.897 & 0.170 \\
\hline 1 & $D D$ & - & -0.050 & 0.073 & - & - \\
\hline 2 & NI / TA & - & -8.607 & 0.000 & -8.713 & 0.000 \\
\hline 3 & $T L / T A$ & + & 1.929 & 0.008 & 2.188 & 0.002 \\
\hline 4 & $C A / C L$ & - & - & 0.102 & - & 0.148 \\
\hline 5 & Sales / TA & - & - & 0.199 & - & 0.203 \\
\hline 6 & $\ln T A$ & - & -0.472 & 0.002 & -0.459 & 0.002 \\
\hline 7 & $V_{A, \text { avg }} / X_{t}$ & + & - & 0.784 & - & 0.263 \\
\hline \multicolumn{3}{|c|}{ Total observations } & & 310 & & 310 \\
\hline \multicolumn{3}{|c|}{ Defaults } & & 60 & & 60 \\
\hline \multicolumn{3}{|c|}{2 Log likelihood } & & 204.432 & & 207.868 \\
\hline
\end{tabular}

Note: The table shows the logistic regression estimates of the $P D$ model. The coefficient (coeff.) indicates the weight of the variable, in case the variable is significant, the p-value gives an indication of the significance of all variables included in the analysis. The $2 \mathrm{log}$ likelihood (-2LL) value is a goodness of fit measure. The plus and minus in the third column (direction) give an indication of the expected direction of the relationship of the variable.

the $D D$ measure. Model A (including $D D$ ) contains all seven variables, model B excludes the $D D$ variable, to test whether the $D D$ has additional predictive power and how much information this variable adds to the model.

We use forward stepwise selection. The selected significance level for adding a variable in the model is 0.05 and for retaining 0.1 . The minimum sample size recommended is five observations per independent variable. In addition to the overall sample size, the sample size of each group must also be considered. At minimum, the smallest group size must exceed the number of independent variables. As a practical guideline, each group should have at least 20 observations (Hair et al., 2006). These requirements are met.

The logistic regression estimates are presented in the tables 13 and 14. Variables that are not significant and therefore not included in the model are presented without a coefficient, only the p-value to enter is given.

The lower the $-2 \mathrm{LL}$, the better the model fit, indicating that model A has a slightly better model fit than model B (Hair et al., 2006). For model A, the $D D$ variable was added in the third step of the four of the logistic regression process, which reduced the $-2 \mathrm{LL}$ with 10.200 . This increase in model fit is statistically significant at the 0.001 level. 
TABLE 14. Correlation matrix model $A$, including the $D D$ variable

\begin{tabular}{rrrrrr}
\hline & & 1 & 2 & 3 & 4 \\
\hline 1 & $D D$ & 1.000 & & & \\
2 & $N I / T A$ & 0.004 & 1.000 & & \\
3 & $T L / T A$ & 0.150 & 0.162 & 1.000 & \\
4 & $\ln T A$ & 0.059 & 0.023 & 0.186 & 1.000 \\
\hline
\end{tabular}

Concluding, the goodness of fit tests indicate that both $P D$ models have good model fit, however, model A (incl. $D D$ ) slightly outperforms model B (excl. $D D)$.

The correlation matrix in table 14 indicates that the model variables do not exhibit high levels of multicollinearity. The direction of the relationship that reflects the changes in the dependent variable associated with changes in the independent variable is also examined. A positive sign symbolizes that an increase in the ratio leads to an increase in the default probability and a negative sign symbolizes a decrease in the default probability given an increase in the ratio. All significant variables have the expected sign.

The significant variables of model $\mathrm{A}$ in predicting default are: $D D$, NI/TA, TL/TA and In TA. Model B contains the same variables except for the $D D$. The results indicate that the structural form model output is significant in default prediction of SMEs and that this variable has some additional predictive power, next to the significant financial ratios (profitability, solvency and size).

Overall, the results indicate that the $D D$ variable is a good indicator of default that can be used on its own, or as an additional variable in a credit risk model.

\section{Applicability of the Methodology}

The model, presented in this research, gives an indication of the credit risk of SMEs, and can be used on its own, or, for example, as an additional variable in a credit risk model.

The model is developed on a sample of Dutch private firms, and is tested on Dutch private firm data. However, the general methodology worked out in this paper can be used in other settings. It can also be used for public companies.

Some of the factors are country or industry specific such as the asset volatility, the expected return on assets, and the optimal $\beta$. These factors can be influenced by differences in accounting standards, culture or 
bankruptcy codes. The model can be made industry or company size specific by using the industry and/or size asset volatilities and return on assets and by determining the optimal beta and cut-off point for the type of companies that are studied.

\section{Conclusion}

SMEs have specific peculiarities that influence the modelling of credit risk. A $P D$ model for SMEs should have the following characteristics: time and cost efficient, broadly applicable, requiring limited financial data, and powerful enough to discriminate between good and bad credit. The goal of this research is to develop a structural form $P D$ model for SMEs, that meets these SME characteristics, and to test the applicability in practice.

A structural form model needs six variables to determine the probability of default of a firm: assessment period, market value of assets, volatility of assets, expected return on assets, default boundary, and the distribution of assets. A methodology for the determination of these variables is worked out, based on the SME characteristics.

The results of the model are promising. Based on a holdout sample of 310 companies, about $63.8 \%$ of the SMEs are predicted correctly out-of-sample as a defaulted or non-defaulted company using the structural form model. The model output differs significantly between defaulted and non-defaulted firms. To test the out-of-sample significance of the $D D$ variable in default prediction compared to popular financial ratios, a second $P D$ model is generated using logistic regression. The results indicate that the structural form model output is significant in default prediction of SMEs and that this variable has some additional predictive power, next to the significant financial ratios (profitability, solvency and size). Overall, the results indicate that the structural form model is a good indicator of default of SMEs that can be used on its own or as an additional variable (the distance to default: $D D$ ) in a credit risk model.

Accepted by: Prof. R. Taffler, Guest Editor, May 2009

Prof. P. Theodossiou, Editor-in-Chief, June 2009

\section{References}

Allen, L.; DeLong, G.; and Saunders, A. 2004. Issues in the credit risk 
modelling of retail markets. Journal of Banking \& Finance 28 727-752.

Altman, E.I. 1968. Financial ratios, discriminant analysis and the prediction of corporate bankruptcy. Journal of Finance 23 4: 589-609.

Altman, E.I.; Haldeman, R.G.; and Narayanan, P. 1977. ZETA ${ }^{\mathrm{TM}}$ analysis, a new model to identify bankruptcy risk of corporations. Journal of Banking and Finance 1: 29-54.

Altman, E.I. 2000. Predicting Financial Distress of Companies: Revisiting the Z-score and Zeta ® Models. www.defaultrisk.com.

Altman, E.I., and Sabato, G. 2007. Modelling Credit Risk for SMEs: Evidence from the US Market. ABACUS, Vol. 43. No. 3.

Åstebro, T., and Winter, J.K. 2002. More than a Dummy: The Probability of Failure, Survival and Acquisition of Firms in Financial Distress. SSRN.

Baas, T., and Schrooten, M. 2005. Relationship Banking and SMEs. A Theoretical Analysis. DIW Discussion Papers 469.

Back, B.; Laitinen, T.; Sere, K.; and van Wezel, M. 1996. Choosing Bankruptcy Predictors Using Discriminant Analysis, Logit Analysis, and Genetic Algorithms. www.defaultrisk.com.

Balcaen, S., and Ooghe, H. 2004. 35 Years of business failure: An overview of the classic statistical methodologies and their related problems. British Accounting Review 38 1: 63-93.

Basel Committee on Banking Supervision. 2006. International convergence of capital measurement and capital Standards. www.bis.org.

Basel Committee on Banking Supervision. 2005. Working Paper No. 14. Studies on the Validation of Internal Rating Systems. www.bis.org.

Basel Committee on Banking Supervision. 2001. Working Paper on the Internal Ratings-Based Approach to Specialised Lending Exposures. www.bis.org.

Beaver, W. H. 1966. Financial ratios as predictors of failure. Journal of Accounting Research. Vol.4, 71-111.

Berger, A.N., and Udell, G.F. 1998. The economics of small business finance: The roles of private equity and debt markets in the financial growth cycle. Journal of Banking and Finance 22.

Bhatia, M. 2006. Credit risk management \& Basel II. Riskbooks.

Black, F., and Cox, J. 1976. Valuing corporate securities: Some effects of bond indenture provisions. Journal of Finance 31 2: 351-367.

Black, F., and Scholes, M. 1973. The pricing of options and corporate liabilities. Journal of Political Economy. 81 3. 637-654.

Burgstahler, D.C.; Hail, L.; and Leuz, C. 2006. The Importance of Reporting Incentives: Earnings Management in European Private and Public Firms. The Accounting Review Vol. 81, No. 5.

Cooper, D. R., and Schindler, P.S. 2003. Business Research Methods. McGrawHill.

Copeland, T.E., 2000. Valuation, Measuring and Managing the Value of Companies. Wiley. Third edition.

Crosby, P., and Bohn, J. 2003. Modeling default risk. www.moodyskmv.com. 
Damodaran, A. 2002. Investment Valuation. Tools and techniques for determining the value of any asset. John Wiley \& Sons.

Degryse, H., and Van Cayseele, P. 2000. Relationship Lending within a Bank-Based System: Evidence from European Small Business Data. Journal of Financial Intermediation 9, 90-109.

Dietrich, J.R., and Kaplan, R.S. 1982. Empirical analysis of the commercial loan classification decision. The Accounting Review LVII 1, 18-38.

Dietsch, M., and Petey, J. 2002. The credit risk in SME loans portfolios: Modelling issues, pricing, and capital requirements. Journal of Banking and Finance 26: 303-322.

Duffie, D., and Singleton, K.J. 1999. Modeling term structures of defaultable bonds. Review of Financial Studies 12, 687-720.

Edminster, R.O. 1972. An empirical test of financial ratio analysis for small business failure prediction. The Journal of Financial and Quantitative Analysis 7 2: 1477-1493.

Engelmann, B.; Hayden, E.; and Tasche, D. 2003. Testing Accuracy Ratio. Risk January 2003.

European Commission. 2001. Amending recommendation 96/280/EC concerning the definition of small and medium-sized enterprises. ec.europa.eu.

Fagiolo, G., and Luzzi, A. (2006). Do liquidity constrains matter in explaining firm size and growth? Some evidence from the Italian manufacturing industry. Industrial and Corporate Change, 15, 1-39.

Falkenstein, E.; Boral, A.; and Carty, L.V. 2000. RiskCalcTM for private companies: Moody's default model rating methodology. www.moodyskmv.com.

Foster, G. 1986. Financial statement analysis. Second Edition. Prentice-Hall.

Hair, J.F.; Black, W.C.; Babin, B.J.; Anderson, R.E.; and Tatham R.L. 2006. Multivariate Data Analysis, Sixth Edition, Prentice Hall.

Huang, J-Z., and Huang, M. 2002 (revised May 2003). How much of the corporate-treasury yield spread is due to credit risk? Results from a new calibration approach. Working Paper. GBS. Stanford University.

Jarrow, R.A., and Turnbull, S.M. 1995. Pricing options on financial securities subject to default risk. Journal of Finance. L 1: 53-85.

Joos, Ph.; Ooghe, H.; and Sierens, N. 1998. Methodologie bij het opstellen en beoordelen van kredietclassificatiemodellen. Tijdschrift voor Economie en Management. XLIII 1.

Kealhofer, S. 2003. Quantifying credit risk I: Default prediction. Financial Analysts Journal 2003 59: 30-44.

Laitinen, E.K. 1992. Financial ratios and different failure processes. Journal of Business Finance and Accounting. 18 649-673.

Leland, H. E. 2004. Predictions of default probabilities in structural models of debt. Working paper. www.haas.berkeley.edu/finance.

Liao, H., and Chen, T. 2005. A multi-period corporate credit model---an 
intrinsic valuation approach. Working Paper. www.ssrn.com.

Longstaff, F. A., and Schwartz, E. S. 1995. A simple approach to valuing risky fixed and floating rate debt. Journal of Finance 50: 789-819.

McClave, J.T.; Benson, P.G.; and Sincich, T. 1998. Statistics for Business and Economics. Seventh Edition. Prentice Hall International, Inc.

McQuown, J.A. 1993. A comment on Market vs. Accounting-Based measure of default risk. Www.moodyskmv.com.

Merton, R. 1974. On the pricing of corporate debt: The risk structure of interest rates. Journal of Finance 29: 449-470.

Ohlson, J.A. 1980. Financial ratios and the probabilistic prediction of bankruptcy. Journal of Accounting Research 18 1: 109-131.

Palepu, K.G.; Healy, P.M.; and Bernard, V.L. 2004. Business analysis \& Valuation, using financial statements. Thomson South Western.

Peterson, M.A. 1999. The small business lending relationship. Conference on Consumer Transactions and Credit. Federal Reserve Bank of Philadelphia.

Petersen, C.; Plenborg, T.; and Schøler, F., 2006. Issues in the valuation of privately held firms. The Journal of Private Equity. 10, 1.

Rijken, H.A. 2005. De gevolgen van Basel II voor de individuele MKB-onderneming blijven onzeker. Accounting 5.

Rivaud-Danset, D.; Dubocage, E.; and Salais, R. 1998. Comparison between the financial structure of SMES and that of large enterprises (LES) using the BACH database. http://europa.eu.int/economy_finance.

Saunders, A., and Allen, L. 2002. Credit risk measurement. New approaches to value at risk and other paradigms. John Wiley \& Sons. Inc.

Schröder, M. 2003. Brownian excursions and Parisian barrier options: a note. Journal of Applied Probability. Vol. 40. No. 4. pp. 855-864.

Shumway, T. 1999. Forecasting bankruptcy more accurately: a simple hazard model. www.ssrn.com.

Sobehart, J., and Keenan, S. 2001. Measuring default accurately. Risk 14: 31-33.

Sobehart, J.R.; Keenan, S.C.; and Stein, R. (2000) Validation methodologies for default risk models, Credit 1(4), p. 51-56.

Standard \& Poor's. 2007. Annual 2006 Global Corporate Default Study and Ratings Transitions. www2.standardandpoors.com.

Stolowy, H., and Lebas, M.J. 2002. Corporate Financial Reporting. A Global Perspective. First Edition. Thomson.

Stickney, C.P., and Weil, R.L. 1997. Financial Accounting. An Introduction To Concepts, Methods, and Uses. Eight Edition. The Dryden Press.

Taffler, R. J. 1982. Forecasting company failure in the UK using discriminant analysis and financial ratio data. Journal of the Royal Statistical Society. Series A (General). 145 3: 342-358.

Weston, J.F.; Siu, J.A.; and Johnson, B.A. 2001. Takeover, restructuring, and corporate governance. Prentice Hall. Third Edition. 